\title{
Sketching the cinematic scientist
}

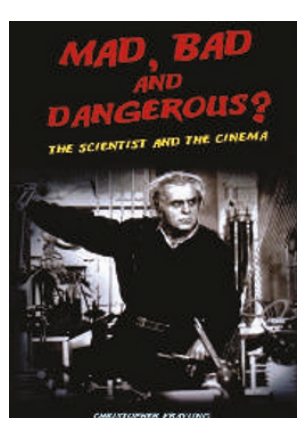

\section{Mad, Bad and Dangerous? The Scientist and the Cinema}

\author{
Christopher Frayling
}

Reaktion Books $\bullet 2005$

$\$ 35.00 / £ 9.95$

\section{Jay P. Telotte}

Christopher Frayling has authored a number of well-respected works on popular film genres that have a reputation for solid historical grounding and insightful commentary. His new book, Mad, Bad and Dangerous? The Scientist and the Cinema, takes on a popular and timely cinematic subject-the role of the scientist, mad and otherwise, in popular filmand again displays his thorough knowledge of his material. However, it does not quite lead the way in this area or provide the level of insight on the topic that has typified his work. Still, Mad, Bad and Dangerous? is highly readable and informative, even for those familiar with other recent books on this topic.

Although Frayling's announced scope is the changing image of the film scientist, his real concern is never simply our varied view, or more precisely, Hollywood's views, but rather the ways in which the US and Western Europe have constructed a cultural concept of the scientist and science. He emphasizes that the meanings of science derive not just from the scientific community, but also from a range of cultural texts, especially the cinema; he believes that understanding these constructions, particularly as film, for much of its history, has been telling its audiences "that science and technology, actually or potentially, are likely to be very bad for them," is crucial in a time when such concerns seem to influence every aspect of our lives.

Although focusing primarily on dominant Hollywood images (particularly those found in horror, science fiction, and biopics of the 1930s and 1940s, and to a lesser extent on British entries of the 1940s and 1950s), Frayling draws in science fiction novels, comics, television and other popular culture artefacts, to chart the evolving public perception of scientists. He adds an interesting note to this survey by including several polls of British scientists' opinions and schoolchildren's attitudes towards science and scientists. These accounts help to demonstrate dramatically what he terms "the gap between specialized knowledge and public understanding" - a gap that leads to stereotypes of the scientist and of what it means to "do science" and contributes to those "anxieties, moral conflicts and social concerns" that inflect most of our cultural discussions about the work of science and scientists.

In this overview, Frayling makes a particularly valuable observation about the cinematic depiction of science and the scientist. He notes that

Jay P. Telotte is in the School of Literature, Communication, and Culture at Georgia Institute of Technology, Atlanta, GA 30332-0165, USA.

e-mail: jay.telotte@lcc.gatech.edu along with the demise of the biopic of the 1930s and 1940s, reflecting a cultural shift from 'great man' stories as ways of organizing our cultural knowledge, our films have correspondingly altered their narratives about science, with the scientist becoming less often the key focus and thus less often the subject of attack. Consequently, Frayling notes, the mad scientist has largely receded to the background, even practically disappeared from film and been replaced by "surrogate villains" a nearly interchangeable cast of "business-people or politicians or soldiers or administrators who treat scientists badly" and serve to "draw the audience's fire." It is an interesting observation, as it suggests the increasing influence of realworld conditions, including those that weigh on the scientist, in shaping our narratives about science and scientists.

Mad, Bad and Dangerous? is highly readable and informative, even for those familiar with other recent

\section{books on this topic.}

Despite such intriguing observations, much of this material has a familiar ring. In the era of what is sometimes termed the "Science Wars", as the field of Cultural Studies argues that science is itself a cultural construction rather than a purely objective field of inquiry, a number of books have already followed this path. Most notably, Andrew Tudor's Monsters and Mad Scientists (1989) and David J. Skal's Screams of Reason: Mad Science and Modern Culture (1998) have provided entertaining and thoughtful tours of this cinematic landscape, charting the various scientists and monstrous creations of our films against the latest scientific and technological developments. In fact, Skal's book provides a more detailed (and a bit more entertaining) look at this material, although his aim is different: to help us understand how our cinematic scientists and their often 'mad science' help us to cope with the cultural chasm between hard science and superstition or popular opinion. The fact that Frayling liberally cites both works shows he has done his homework, and his persistence in producing this book in the wake of these other fine efforts suggests he has another purpose.

That purpose is best seen in Frayling's concluding emphasis that "popular images matter", even though they sometimes exaggerate and produce misperceptions. Although this point might seem almost a cliche today, it allows for an important complication: he suggests that these images "can be challenged," indeed, that we must do so to "raise the quality of public discourse" about the role of science and technology in our lives. Although Mad, Bad and Dangerous? offers no prescription for how to close what Carl Sagan termed the "communication gap" between the public and the scientific establishment, it does help map the anxiety-laden cultural territory where science, technology, and everyday life meet and generate both disturbing and compelling cultural narratives, and that is a significant accomplishment. 